\title{
The clinical utility of preoperative surgical risk indices and ICU bed allocation on outcomes of noncardiac surgical patients: A cohort study
}

\author{
Demetrios J. Kutsogiannis ${ }^{1}$, Sean Norris ${ }^{1}$, Becky K. L. Leung ${ }^{2}$ \\ ${ }^{1}$ Division of Critical Care Medicine, Faculty of Medicine and Dentistry, University of Alberta, Edmonton, Canada \\ ${ }^{2}$ Division of Cardiology, Faculty of Medicine and Dentistry, University of Alberta, Edmonton, Canada \\ Email: jim.kutsogiannis@ualberta.ca
}

Received 5 September 2012; revised 8 October 2012; accepted 20 October 2012

\begin{abstract}
Summary statement: In non-cardiac surgical patients, respiratory failure index and intensivists' (expert) opinion predicted postoperative mortality and respiratory failure. Intermediate risk patients allocated to postoperative ICU care vs. surgical high intensity care demonstrated increasing lengths of hospital stay. Background: No guidance exists for allocating postoperative ICU resources for patients undergoing noncardiac surgery. We determined the predictive value of preoperative risk sores and "expert opinion" in predicting postoperative mortality and complications. Methods: A cohort study involving 403 adults undergoing elective noncardiac surgery and being assessed in a preoperative clinic within a university affiliated tertiary care hospital. Postoperative outcomes included 30-day mortality, respiratory failure at 48hour, unplanned intubation, cardiac composite score, hospital length of stay, hypotension, hypertension, and delirium. Results: Preoperative respiratory failure index (PRFI) predicted 30-day mortality (OR 1.11, 95\% CI 1.04 to 1.19). An intensivist's opinion predicted respiratory failure 48-hour postoperatively (OR 28.70, 95\% CI 7.44 to 110.70). Patients with an equivalent PRFI risk had a longer hospital stay (17.2 v. 8.9 days, $P=0.01)$, increased respiratory failure risk $(P=0.009)$, hypertension $(P=0.009)$, hypotension $(P=0.005)$ and delirium $(P=0.05)$ if allocated to an ICU bed versus a high-intensity bed. Conclusions: PRFI predicts 30-day postoperative mortality and cardiac events. A decision to allocate an ICU bed predicted the development of postoperative respiratory failure. Patients with an intermediate PRFI risk and allocated to an ICU demonstrated increasing lengths of hospital stay and morbidity.
\end{abstract}

Keywords: Risk Factors; Comorbidity; Postoperative Complications

\section{INTRODUCTION}

The aging of the United States population in the next two decades will increase the burden of acute and chronic illness and the demand for critical care services [1]. In 2004, 33\% of Medicare hospitalizations had intensive care unit (ICU) or coronary care unit care representing an annual increase in costs of $36 \%$ to $\$ 32.3$ billion from 1994 [2]. In Ontario, the crude incidence of mechanically ventilated adults with noncardiac surgical and medical diagnoses between 2000 and 2026 is projected to increase $31 \%$ from 222 to 291 per 100,000 adults. As a significant proportion of critical care is devoted to the care of postoperative patients, improved efficacy is expected in the delivery of critical care services to elective postoperative patient [3]. Several statistical models have been validated to risk stratify patients undergoing noncardiac surgery and using both cardiac and respiratory outcomes $[4,5]$. Two of the most robust models include the preoperative respiratory failure risk index (PRFI) and the revised cardiac risk index (RCRI) [6,7]. In an effort to reduce the heterogeneity of post-operative morbidity and mortality across hospitals, post-operative events such as respiratory failure, myocardial infarction and surgical site infections represent benchmarks for measuring the variation in quality of hospitals [8,9]. However, despite large numbers of patients undergoing noncardiac operations worldwide, there are no randomized trials demonstrating the effectiveness of ICU care for subgroups of noncardiac surgical patients [10].

The primary objective of this cohort study was to determine the predictive value of the preoperative respiratory failure index (PRFI) the revised cardiac risk index (RCRI), and the "expert opinion" of a group of intensive care physicians after consultation with anesthesiologists, in predicting the development of post operative respiratory and cardiac events and mortality in a population of elective noncardiac surgical patients. The secondary objective of this study was to explore whether there existed 
any difference in complication rates and length of hospital stay between those patients within similar PRFI categories allocated to and receiving a postoperative ICU bed versus those patients not allocated to nor receiving a postoperative ICU bed by "expert opinion".

\section{MATERIALS AND METHODS}

From January 2002 to December 2004, patients were consented in a preoperative clinic of a 550 bed, university affiliated tertiary care hospital in Edmonton, Canada. The study was approved by the Human Research Ethics Board, University of Alberta, and 403 provided written informed consent to participate. Inclusion criteria included all patients undergoing abdominal, vascular, thoracic and head and neck procedures and requiring the preoperative consultation of at least one non-surgical specialist. For those undergoing general, orthopaedic or neurosurgical procedures, an additional requirement of at least one comorbid medical condition was required for enrolment into the study. Orthopaedic surgical patients were only included during the first year of the study (Appendix 1).

During each week, one of seven rotating intensivists was responsible for allocating a postoperative ICU bed, surgical high intensity bed or surgical ward bed during the patient's preoperative risk assessment based on their "expert opinion". Intensivists were not provided with PRFI and RCRI scores. Preoperative cardiac risk was determined using the RCRI which previously utilized a derivation cohort of 2893 patients [7]. In the validation cohort of 1422 patients, a RCRI score of 0 (RCRI-I), 1 (RCRI-II), 2 (RCRI-III), and $\geq 3$ (RCRI-IV) predicted a $0.4 \%, 0.9 \%, 6.6 \%$, and $11.0 \%$ frequency of major cardiac complications. The history of angina and congestive heart failure were recorded using the Canadian Cardiovascular Society Classification and the New York Heart Association Classification respectively [11,12]. Postoperative respiratory risk was determined using the PRFI which has been previously derived using a cohort of 81,719 patients undergoing noncardiac surgery. In the validation cohort of 99,390 patients, a PRFI score of $\leq 10$ (PRFI-I), 11 - 19 (PRFI-II), 20 - 27 (PRFI-III), 28 - 40 (PRFI-IV) and $>40$ (PRFI-V) predicted a $0.5 \%, 2.2 \%$, $5.0 \%, 11.6 \%$ and $30.5 \%$ frequency of respiratory failure respectively [6]. Within the PRFI score, patients undergoing abdominal aortic aneurysm or thoracic surgery score the highest number of points followed by neurosurgery/upper abdominal/peripheral vascular and neck surgery. Body mass index was defined as the weight in kilograms divided by the square of the patient's height in meters. Forced expiratory volume in one second was measured either by formal pulmonary function testing or using bedside spirometry. If the "expert opinion" of the intensivist deemed that the patient required the assignment to an ICU bed, the surgery was not undertaken unless an ICU bed was available on the morning of the planned surgery. The surgical high-intensity unit was staffed with a 1:2 nurse-to-patient ratio with continuous arterial blood pressure monitoring, pulse oximetry, and non-invasive ventilation if necessary. However, the highintensity unit could not provide mechanical ventilation or inotropic/vasopressor support. The surgical ward did not offer continuous blood pressure monitoring or continuous oximetry, non-invasive or mechanical ventilation, or inotropic/vasopressor support.

Predictor (independent) variables for the primary postoperative outcomes included "expert opinion", RCRI, PRFI, body mass index (BMI), and forced expiratory volume in 1 second (FEV1). The primary outcome (dependent) variables included mortality at day 30 , postoperative respiratory failure (defined as requiring either mechanical or non-invasive ventilation 48 hours postoperatively), unplanned intubation, and a cardiac composite score. A hypothesis generating exploratory analysis was also undertaken comparing those allocated to the ICU by "expert opinion" versus those not allocated to the ICU and stratified by RFRI categories to assess the secondary outcomes of hospital length of stay, hypotension, hypertension, and delirium. Postoperative respiratory failure was defined according to the original validation of the PRFI, as the requirement for mechanical ventilation or non-invasive ventilation for more than 48 hours after surgery [6]. A cardiac composite score was created which was calculated as the sum of the presence of each of myocardial infarction, pulmonary oedema, ventricular fibrillation, primary cardiac arrest, and complete heart block. Myocardial infarction was defined as a rise in serum troponin above the upper limit of normal with or without associated ECG changes (Q-waves) and documented as such on the medical record. Pulmonary oedema was defined as respiratory distress with evidence of fluid accumulation in the lungs by clinical exam, chest $\mathrm{X}$-ray, or invasive monitoring. Hypotension and hypertension was defined as having a systolic blood pressure $\leq 90 \mathrm{mmHg}$ or $\geq 160 \mathrm{mmHg}$ and requiring intervention or deemed clinically significant by the attending physician. Delirium was defined as a confusional state marked by a prominent disorder of perception, terrifying hallucinations and vivid dreams, a kaleidoscopic array of strange and absurd fantasies and delusions, inability to sleep, tendency to convulse, and intense emotional disturbance [13]. The Logistic Organ Dysfunction (LOD) score was calculated as a measure of illness severity in those patients who were admitted into the ICU postoperatively $[13,14]$. All outcome measures were ascertained both prospectively and by a retrospective chart review. 


\section{STATISTICAL ANALYSIS}

Frequency distributions, means, and medians were determined for all variables and postoperative complications. Significant differences in the distribution of variables existed if the two-tailed $\mathrm{P}$ value was $<0.05$ as determined by a chi-square test, or Fisher's exact test for categorical variables, and the t-test, Wilcoxon rank sum test, or test for the equivalence of medians for continuous variables. The RCRI, PRFI, BMI, and FEV1 have been previously found to predict postoperative cardiac and pulmonary complications, and these in addition to "expert opinion", were included as independent variables in a stepwise logistic regression analysis using the following dependent variables: 1) mortality 30 days postoperatively; 2) respiratory failure 48 hours postoperatively; 3 ) unplanned intubation; 4) cardiac composite score or respiratory failure; and 5) cardiac composite score or mortality 30 days postoperatively. A significance level of $\leq 0.05$ was selected for variable retention in the final model after backwards selection. The analysis was performed in S-Plus version 6.01 and STATA version 10.

\section{RESULTS}

\subsection{Patient Demographics and Disposition}

A total of 403 patients were included in the analysis. The majority of patients were in the age group of 70 to 79 years, male, and undergoing a general surgical procedure. Fourty-nine patients $(12.1 \%)$ and 18 patients $(4.5 \%)$ had a PRFI score of 28 - 40 (PRFI-IV) and $>40$ (PRFI-V). Eighty patients $(19.9 \%)$ and 26 patients $(6.5 \%)$ were in categories RCRI-III and RCRI-IV respectively (Table 1). Sixteen patients $(4.0 \%)$ returned to the operating theatre for a repeat operation and 13 of these operations were related to a complication from the initial surgery. A total of 46 patients $(11.4 \%)$ were allocated an ICU bed preoperatively. Of these, 40 patients went to the ICU postoperatively and 6 patients were deemed stable enough to be transferred directly the high intensity unit. Twelve additional patients $(3.0 \%)$ were not allocated an ICU bed preoperatively but were transferred to an ICU bed from the operating theatre or surgical ward. Eighty-six patients $(21.3 \%)$ had a high intensity bed allocated preoperatively where they were cared for postoperatively. An additional $21(5.2 \%)$ patients did not have a high intensity bed allocated preoperatively, but were transferred to the high intensity unit from the operating theatre or surgical ward. Ultimately 52 (12.9\%), 113 (28.0\%), and 238 (59.1\%) patients required ICU, high intensity and surgical ward care as their highest level of postoperative care [Appendix 2]. Five of 403 patients (1.2\%) were lost to follow-up after hospital discharge and were not included in the 30-day mortality multivariable analysis.
Table 1. Characteristics of the study population.

\begin{tabular}{|c|c|c|}
\hline Age & $\mathrm{N}=\mathbf{4 0 3}$ & \\
\hline & $\leq 49$ & $49(12.2)$ \\
\hline & 50 to 59 & $84(20.8)$ \\
\hline & 60 to 69 & $94(23.3)$ \\
\hline & 70 to 79 & $131(32.5)$ \\
\hline & 80 to 89 & $44(10.9)$ \\
\hline & $\geq 90$ & $1(0.3)$ \\
\hline \multicolumn{3}{|l|}{ Gender } \\
\hline & Male & $226(56.1)$ \\
\hline & Female & $177(43.9)$ \\
\hline \multicolumn{3}{|l|}{ Type of surgery } \\
\hline & General surgery & $175(43.4)$ \\
\hline & Vascular surgery & $122(30.3)$ \\
\hline & Orthopaedic surgery & $56(13.9)$ \\
\hline & Thoracic surgery & $39(9.7)$ \\
\hline & Neurosurgery & $11(2.7)$ \\
\hline \multicolumn{3}{|l|}{$\begin{array}{l}\text { Preoperative Respiratory } \\
\text { Failure Index (PRFI) }\end{array}$} \\
\hline & $<20$ & $207(51.4)$ \\
\hline & 20 to 27 & $125(31.0)$ \\
\hline & 28 to 40 & $53(13.2)$ \\
\hline & $>40$ & $18(4.5)$ \\
\hline \multicolumn{3}{|l|}{$\begin{array}{l}\text { Revised Cardiac Risk } \\
\text { Index (RCRI) }\end{array}$} \\
\hline & Class I & $98(24.3)$ \\
\hline & Class II & $199(49.4)$ \\
\hline & Class III & $80(19.9)$ \\
\hline & Class IV & $26(6.5)$ \\
\hline \multicolumn{3}{|l|}{$\begin{array}{c}\text { Logistic organ } \\
\text { dysfunction score } \\
(\mathrm{N}=40 \text { ICU patients) }\end{array}$} \\
\hline & $\leq 1$ & $12(24.0)$ \\
\hline & 2 to 4 & $22(44.0)$ \\
\hline & 5 to 7 & $11(22.0)$ \\
\hline & 8 to 10 & $5(10.0)$ \\
\hline \multirow[t]{4}{*}{ Body mass index, $\mathrm{kg} / \mathrm{m}^{2}$} & $<30$ & $236(58.6)$ \\
\hline & 30 to 40 & $119(29.5)$ \\
\hline & 41 to 50 & $32(7.9)$ \\
\hline & $>50$ & $16(4.0)$ \\
\hline FEV-1 (L), mean (SD) & & $2.19(0.75)$ \\
\hline
\end{tabular}




\subsection{Mortality, Respiratory and Cardiac Outcomes}

Five patients $(1.2 \%)$ died within 30 days of their operation, $12(3.0 \%)$ met the criteria for postoperative respiratory failure at 48 -hrs, $16(4.0 \%)$ required an unplanned intubation at any time postoperatively and 27 (6.7\%) suffered at least one major cardiac event post-operatively. Nine of the $16(56.3 \%)$ who required an unplanned intubation were allocated to and received an ICU bed immediately postoperatively whereas the remaining 7 (43.7\%) received high intensity or surgical ward care immediately postoperatively. An increasing PRFI was associated with an increasing RCRI $(P=0.0001)$. There was a significant association between the PRFI and 30-day mortality ( $\mathrm{P}=$ $0.04)$, respiratory failure $(\mathrm{P}<0.0001)$, and unplanned intubation $(\mathrm{P}=0.005)$. Both the incidence of cardiac events as measured by the cardiac composite score $(\mathrm{P}<$ $0.0001)$ and the incidence of hypertension $(\mathrm{P}<0.0001)$ increased with each increasing level of PRFI. The median [mean] (4.0 [6.7] versus 9.2 [16.4] days) hospital length of stay increased significantly between the PRFII/II group (score 0 to 20) and the PRFI-V group (score $>$ 40) $(\mathrm{P}<0.001)$. There was no association between RCRI score and hospital mortality $(\mathrm{P}=0.43), 30$-day mortality $(\mathrm{P}=0.43)$, or the development of respiratory failure $(\mathrm{P}=$ $0.21)$. However, there was an association between requiring an unplanned intubation and increasing RCRI score $(\mathrm{P}=0.03)$. As expected, a significant association did exist between an increasing RCRI score and both the cardiac composite outcome $(\mathrm{P}=0.0001)$ and postoperative hypertension $(\mathrm{P}=0.05)$ (Table 2). The 5 patients who died within 30 days of their operation had a significantly higher mean PRFI (35.4 versus $18.3, \mathrm{P}=0.001$ ), and were significantly more likely to have undergone an unplanned intubation ( $40 \%$ versus $3.5 \%, \mathrm{P}=0.003$ ) than surviving patients. The etiology of death in these five patients included myocardial infarction, peritonitis, and multisystem organ failure and the preoperative allocation of an ICU bed by "expert opinion" was not associated with 30-day mortality $(\mathrm{P}=0.19)$.

"Expert opinion", RCRI, PRFI, BMI, and FEV1 were included in logistic regression models predicting 30-day mortality, development of respiratory failure, unplanned intubation, mortality or cardiac composite score $\geq 1$, and respiratory failure or cardiac composite score $\geq 1$. Only the PRFI score (OR 1.11, 95\% CI 1.04 - 1.19) remained significantly predictive of 30 -day mortality in the multivariable model. However only "expert opinion" (OR $28.70,95 \%$ CI 7.44 - 110.70) independently predicted postoperative respiratory failure. Revised cardiac risk index (OR 2.00, 95\% CI 1.12 - 3.57), PRFI (OR 1.06, 95\% CI 1.01 - 1.11) and BMI (OR 1.07, 95\% CI 1.02 - 1.12) were independent predictors of an unplanned intubation in the multivariable model. Both the PRFI and "expert opinion" remained as independent predictors of the combined outcomes, cardiac composite score of $\geq 1$ or 30-day mortality, and cardiac composite outcome of $\geq 1$ or respiratory failure at 48 hours (Table 3). Collinearity between

Table 2. (a) Outcomes by preoperative respiratory failure index (PRFI); (b) Outcomes by revised cardiac risk index (RCRI).

(a)

\begin{tabular}{|c|c|c|c|c|c|}
\hline Outcome ${ }^{*}$ & PRFI-I \& II $(n=207)$ & PRFI-III $(\mathrm{n}=125)$ & PRFI-IV $(\mathrm{n}=53)$ & PRFI-V $(\mathrm{n}=18)$ & P-value \\
\hline In-hospital mortality & $0(0.0 \%)$ & $2(1.6 \%)$ & $2(3.8 \%)$ & $1(5.6 \%)$ & 0.04 \\
\hline 30-day mortality & $0(0.0 \%)$ & $2(1.6 \%)$ & $2(3.8 \%)$ & $1(5.6 \%)$ & 0.04 \\
\hline 48-hr respiratory failure & $2(1.0 \%)$ & $1(0.8 \%)$ & $6(11.3 \%)$ & $3(16.7 \%)$ & $<0.0001$ \\
\hline Unplanned intubations & $3(1.5 \%)$ & $6(4.8 \%)$ & $4(7.5 \%)$ & $3(16.7 \%)$ & 0.005 \\
\hline Cardiac composite score $\geq 1$ & $4(1.9 \%)$ & $8(6.4 \%)$ & $9(17.0 \%)$ & $6(33.3 \%)$ & $<0.0001$ \\
\hline $\begin{array}{l}\text { Hospital length of stay, } \\
\text { days median (range) }\end{array}$ & $4.0(1.6-6.8)$ & $5.7(3.7-8.6)$ & $7.8(6.7-10.8)$ & $9.2(6.8-13.7)$ & $<0.001$ \\
\hline
\end{tabular}

(b)

\begin{tabular}{cccccc}
\hline Outcome $^{*}$ & RCRI-I $(\mathrm{n}=98)$ & RCRI-II $(\mathrm{n}=199)$ & RCRI-III $(\mathrm{n}=80)$ & RCRI-IV $(\mathrm{n}=26)$ & P-value \\
\hline In-hospital mortality & $0(0 \%)$ & $3(1.5 \%)$ & $1(1.3 \%)$ & $1(3.8 \%)$ & 0.43 \\
48-hr respiratory failure & $1(1.0 \%)$ & $5(2.5 \%)$ & $5(6.3 \%)$ & $1(3.8 \%)$ & 0.21 \\
Unplanned intubations & $1(1.0 \%)$ & $6(3.0 \%)$ & $6(7.5 \%)$ & $3(11.5 \%)$ & 0.03 \\
$\begin{array}{c}\text { Cardiac composite score } \geq 1 \\
\begin{array}{c}\text { Hospital length of stay, } \\
\text { days median (range) }\end{array}\end{array}$ & $2(2.0 \%)$ & $12(6.0 \%)$ & $7(8.8 \%)$ & $6(23.1 \%)$ & 0.0001 \\
\hline
\end{tabular}


Table 3. Logistic regression models predicting 30-day mortality, respiratory failure (48-hr), unplanned intubation, and cardiac events/ 30 -day mortality or respiratory failure (48-hr).

\begin{tabular}{cccc}
\hline Outcome & Variables & Crude Odds Ratio (95\% CI) & Adjusted Odds Ratio (95\% CI) \\
\hline Mortality 30 days postoperatively & & & $1.11(1.04-1.19)$ \\
Respiratory failure 48-hours postoperatively & PFRI Score & $1.11(1.04-1.19)$ & $28.70(7.44-110.70)$ \\
Unplanned intubation & Expert opinion & $28.70(7.44-110.70)$ & $2.00(1.12-3.57)$ \\
& & & $1.06(1.01-1.11)$ \\
& RCRI Score & $2.47(1.49-4.10)$ & $1.07(1.02-1.12)$ \\
$\begin{array}{c}\text { Cardiac composite outcome score } \geq \mathbf{1} \text { or mortality } \\
\mathbf{3 0} \text { days postoperatively }\end{array}$ & PFRI Score & $1.07(1.02-1.11)$ & $1.08(1.04-1.12)$ \\
& BMI, kg/m & $1.05(1.01-1.10)$ & $2.66(1.03-6.82)$ \\
\hline $\begin{array}{c}\text { Cardiac composite outcome score } \geq \mathbf{1} \text { or respiratory } \\
\text { failure 48-hour postoperatively }\end{array}$ & PFRI Score & $1.09(1.06-1.13)$ & $1.07(1.03-1.10)$ \\
& Expert opinion & $7.06(3.11-16.01)$ & $3.30(1.35-8.07)$ \\
\hline
\end{tabular}

the PRFI and "expert opinion" was investigated by observing for variance inflation or significant point estimate deviation when both parameters were fit into the logistic model as compared to the models containing the individual parameters. Combining the two variables did reduce the magnitude but not the direction of the independent point estimates of "expert opinion" but not of PRFI. However no inflation of variance was noted about the point estimates of the models containing "expert opinion". This indicates that there is some overlap between PRFI and the variables used within the "expert opinion". Interaction terms were not fit in the models given the low mortality.

\subsection{Influence of ICU Bed Allocation}

Two-hundred and seven patients had a PRFI of less than 20 (51.3\% PRFI-I and PRFI-II), 125 had a PRFI of 20 27 (31.0\% PRFI-III), 53 patients had a PRFI of $28-40$ (13.2\% PRFI-IV) and 18 patients had a PRFI of $>40$ (4.5\% PRFI-V). Within PRFI-III to V strata, an ICU bed was not allocated nor was the patient cared for in the ICU immediately postoperatively in $113(90 \%), 27(51 \%)$, and $9(50 \%)$ of patients respectively. Within all PRFI groups, mean RCRI, BMI and FEV1 did not differ significantly between the ICU and non-ICU groups. However, within PRFI-IV, mean PRFI was significantly higher in those patients who were assigned to and received and ICU bed by "expert opinion" versus those patients who were not assigned to and did not receive an ICU bed $(\mathrm{P}<0.0001)$. In those patients within the PRFI-III strata, a longer mean hospital length of stay $(\mathrm{P}=0.002)$ and a higher incidence of hypotension $(\mathrm{P}=0.008)$ was present in those patients who were allocated to and received an ICU bed by "expert opinion" versus those patients who were not allocated to and did not receive an ICU bed. Within the PRFI-IV strata, there was a longer mean hospital length of stay $(P=0.01)$ and a higher incidence of respiratory failure $(\mathrm{P}=0.004)$, hypertension $(\mathrm{P}=0.005)$, and delirium $(\mathrm{P}=0.03)$ in those patients who were allocated to and received an ICU bed versus those patients who were not allocated to and did not receive an ICU bed. Within the PRFI-V strata, there was a longer mean hospital length of stay $(\mathrm{P}=0.02)$ and a higher mean cardiac composite score $(\mathrm{P}=0.02)$ in those patients who were allocated to and received an ICU bed versus those patients who were not allocated to and did not receive an ICU bed (Table 4).

\section{DISCUSSION}

Our study of patients undergoing elective noncardiac surgery demonstrated that the PRFI was the only independent predictor of 30-day mortality. However, only the "expert opinion" of preoperative allocation of a patient to the ICU independently predicted the requirement for mechanical ventilation at 48 -hours. For combined outcomes of postoperative cardiac events or mortality and 
Table 4. Characteristics of discrepant patients by Preoperative Respiratory Failure Index category ${ }^{*}$.

\begin{tabular}{|c|c|c|c|}
\hline \multirow{2}{*}{$\begin{array}{l}\text { Preoperative Respiratory Failure Index } \\
20-27 \text { (PRFI-III) }\end{array}$} & $\begin{array}{l}\text { Allocated to and receiving ICU } \\
\text { (Expert Opinion) }\end{array}$ & $\begin{array}{l}\text { Not allocated to and not receiving ICU } \\
\text { (Expert opinion) }\end{array}$ & P-Value ${ }^{\dagger}$ \\
\hline & $\mathrm{n}=7$ & $\mathrm{n}=\mathbf{1 1 3}$ & \\
\hline PRFI, mean & 23.28 & 22.39 & 0.35 \\
\hline Revised Cardiac Risk Index, mean & 1.571 & 1.168 & 0.15 \\
\hline BMI, $\mathrm{kg} / \mathrm{m}^{2}$ & 34.10 & 29.30 & 0.20 \\
\hline FEV1, L & 1.96 & 2.17 & 0.26 \\
\hline Cardiac composite score, mean & 0.1428 & 0.0973 & 0.81 \\
\hline Cardiac composite score $\geq 1$ & $1 / 7$ & $6 / 113$ & 0.88 \\
\hline Mean hospital length of stay, days & 14.85 (median 11.7) & $12.66($ median 4.75$)$ & 0.002 \\
\hline 30-Day mortality & $0 / 7$ & $2 / 113$ & 0.89 \\
\hline Ventilated at 48 -hour & $0 / 7$ & $1 / 113$ & 0.94 \\
\hline Unplanned intubation & $0 / 7$ & $5 / 113$ & 0.74 \\
\hline Hypotension & $4 / 7$ & $13 / 113$ & 0.008 \\
\hline Hypertension & $0 / 7$ & $8 / 113$ & 0.61 \\
\hline Delerium & $0 / 7$ & $6 / 113$ & 0.69 \\
\hline $\begin{array}{c}\text { Preoperative Respiratory Failure Index } \\
28 \text { - } 40 \text { (PRFI-IV) }\end{array}$ & $\mathbf{n}=\mathbf{2 0}$ & $\mathbf{n}=\mathbf{2 7}$ & \\
\hline PRFI, mean & 35.65 & 31.55 & 0.0001 \\
\hline Revised cardiac risk index, mean & 1.7 & 1.407 & 0.20 \\
\hline BMI, $\mathrm{kg} / \mathrm{m}^{2}$ & 28.878 & 28.049 & 0.60 \\
\hline FEV1, L & 1.804 & 1.937 & 0.36 \\
\hline Cardiac composite score, mean & 0.20 & 0.222 & 0.88 \\
\hline Cardiac composite score $\geq 1$ & $4 / 20$ & $4 / 27$ & 0.94 \\
\hline Mean (median) hospital length of stay, days & $17.19(9.75)$ & $8.93(6.77)$ & 0.01 \\
\hline 30-Day mortality & $1 / 20$ & $1 / 27$ & 0.68 \\
\hline Ventilated at 48 -hour & $6 / 20$ & $0 / 27$ & 0.004 \\
\hline Unplanned intubation & $3 / 20$ & $1 / 27$ & 0.30 \\
\hline Hypotension & $7 / 20$ & $5 / 27$ & 0.31 \\
\hline Hypertension & $11 / 20$ & $4 / 27$ & 0.005 \\
\hline Delerium & $7 / 20$ & $2 / 27$ & 0.03 \\
\hline $\begin{array}{c}\text { Preoperative Respiratory Failure Index }>40 \\
\text { (PRFI-V) }\end{array}$ & $n=8$ & $\mathrm{n}=\mathbf{9}$ & \\
\hline PRFI, mean & 46.0 & 47.44 & 0.52 \\
\hline Revised Cardiac Risk Index, mean & 2.375 & 1.555 & 0.14 \\
\hline BMI, $\mathrm{kg} / \mathrm{m}^{2}$ & 29.69 & 27.55 & 0.92 \\
\hline FEV1, L & 2.272 & 2.415 & 0.75 \\
\hline Cardiac composite score, mean & 0.875 & 0.111 & 0.02 \\
\hline Cardiac composite score $\geq 1$ & $5 / 8$ & $1 / 9$ & 0.09 \\
\hline Mean hospital length of stay, days & 26.45, SD $19.63(25.26)$ & 8.398, SD $2.641(7.72)$ & 0.02 \\
\hline 30-Day mortality & $1 / 8$ & $0 / 9$ & 0.47 \\
\hline Ventilated at 48 -hour & $3 / 8$ & $0 / 9$ & 0.08 \\
\hline Unplanned intubation & $3 / 8$ & $0 / 9$ & 0.08 \\
\hline Hypotension & $3 / 8$ & $2 / 9$ & 0.62 \\
\hline Hypertension & $3 / 8$ & $3 / 9$ & 1.00 \\
\hline Delerium & $2 / 8$ & $2 / 9$ & 1.00 \\
\hline
\end{tabular}

*Two hundred and seven patients with a PRFI-I were not included in this analysis. Analysis was based on 120, 47, and 17 patients in PRFI-III, PRFI-IV, and PRFI-V with available data. 'Fisher's exact test used for categorical comparisons with fewer than 5 observations. 
postoperative cardiac events or the requirement for mechanical ventilation at 48-hour, both PRFI and "expert opinion", but not RCRI, were independent predictors. Collectively, $50 \%$ of patients in PRFI-IV and PRFI-V were allocated to and received an ICU bed postoperatively, demonstrating either the heterogeneity in decision making among the multidisciplinary group of physicians caring for these patients or that the PRFI omits variables which may be relevant to allocating an ICU bed. Collectively, unmeasured comorbidities, unique surgical risks, vacancy and staffing of ICU beds, and/or random decision making may have been influencing the "expert opinion" to allocate an ICU bed. Moreover, those patients with an intermediate or high level of PRFI risk had a significant increase in the risk of respiratory failure, hypotension, hypertension, delirium, and a longer length of hospital stay if allocated to and receiving an ICU bed postoperatively as compared to similar strata of patients not allocated to an ICU bed. Although the design of this study prohibits the inference of a causal link between ICU bed allocation and increased complications, further development of this hypothesis is warranted within future studies. For those with intermediate PRFI risk, the decision to allocate an ICU bed was likely made on the assumption that monitoring a patient in the ICU would improve her outcome as opposed to an assumption that a high likelihood of ICU dependent intervention would be required. Such conservative allocation to an ICU may increase the utilization of scarce ICU and hospital resources, and may have delayed the allocation of patients at very high operative risk or prevented the admission of emergent patients requiring ICU care. The lengthened hospital stay was likely attributable to the a-priori "expert opinion" that mechanical ventilation was necessary for the majority of patients assigned to postoperative ICU care, and that pharmacological interventions were required to maintain a patient sedated to facilitate mechanical ventilation. Delayed discharges from the ICU because of a lack of beds within the high intensity unit or surgical wards may have also contributed to the lengthened hospital stay. Indeed the ICU co-intervention of mechanical ventilation may, in part, be a self-fulfilling prophecy resultant from preoperative ICU bed allocation. The robust association between the PRFI in predicting mortality or respiratory failure in this study is consistent with individual variables comprising the PRFI such as older age, albumin level, renal dysfunction, and thoracic surgery diagnosis individually having demonstrated predictive value in other prospective studies [15-18]. Also consistent with this study is a recent systematic review and cohort study which demonstrated that the RCRI was poor to moderate in discriminating postoperative cardiac events in populations of vascular noncardiac and mixed noncardiac surgical patients $[19,20]$.
Heterogeneous decision making in allocating ICU beds in noncardiac surgery patients has been described elsewhere. In a retrospective study of 241 bariatric patients requiring either ICU or an intermediate care unit, half of these patients were placed into these units in an anticipatory manner with the other half admitted as unexpected emergencies. Upon review of these cases, the authors were unable to discern why individual patients were preemptively placed in the ICU or an intermediate care unit [17]. Other authors have demonstrated a reduced mortality with no worsening morbidities using a strategy of up to 24-hour management in the operative recovery room of preselected patients after elective abdominal aortic surgery [21-23]. Moreover, a propensity case matched retrospective review of 104 pairs of elective neurosurgical patients with American Society of Anaesthesiologists Status I or II failed to demonstrate a difference in Glasgow Outcome Score, mortality, or complication rates between those assigned to ICU care versus neurosurgical ward care postoperatively [24].

The increased utilization of high intensity units which do not provide inotropic/vasopressor support or mechanical ventilation should be considered as an option to ICU care. A decrease in the rate of cancellation of major elective operations with no more than one surgical cancellation for any given patient following the opening of a new high intensity unit has been previously demonstrated [10]. As well, the utilization of post-operative non-invasive continuous positive airway pressure, which may be available within high intensity units such as ours, has been demonstrated to reduce the incidence of respiratory failure, pneumonia, infection, and sepsis in selected patients [25]. Conversely, a more rational use of postoperative interventions requiring ICU admission such as intravenous beta-blockade, pulmonary artery catheter monitoring, and goal directed hemodynamic therapy, which have been found to be of limited benefit in subgroups of patients, may avert the requirement for postoperative ICU admission in such patients [26-29]. A two stage approach to risk stratification including preoperative, operative and immediate post-operative parameters may be considered to improve ICU allocation decisions. Previous studies have demonstrated that one third of postoperative complications and one fourth of deaths occur within the first 48 hours after surgery [30]. These early postoperative complications such as hypotension, hypertension, tachycardia, hypoxemia, hypercapnea, a decreased level of consciousness and operations outside of normal work hours predict unplanned ICU admissions and may add predictive value to preoperative risk factors in the allocation of ICU beds [31-33].

Although patients were analyzed within their respective risk strata in order to limit bias, residual confounding, other unidentified comorbidities, and operative risk 
factors may have accounted for the observed differences in outcomes between groups. Many clinical, biological and operative variables in these patients are complex and it is difficult to achieve a high level of discrimination with current predictive scoring systems in these multifactorial processes [34]. The cohort was limited to one university affiliated tertiary care center with a small number of deaths and respiratory failure events, which may limit the generalizability of the study. Moreover the small number of events limited any inference of potential interactions between the predictor variables. There may also have been ascertainment bias in measuring cardiac outcomes, favoring the assignment of more events to the closely observed ICU group. Also, the possibility of ICU co-intervention bias resulting in harm to those patients cared for in the ICU cannot be excluded and requires further exploration. Although the CAM-ICU has recently become a standard for measuring delirium within the ICU, it was not in universal use at the time this study was initiated $[35,36]$. Consequently, our use of a neurologybased definition of delirium may have also added to ascertainment bias.

There remains a requirement for well designed clinical trials incorporating preoperative, operative and postoperative predictors to assess the effectiveness of ICU care in subgroups of high risk noncardiac surgical patients. Improved standardized protocols for fair allocation of postoperative ICU resources should be developed, concordant with the American Thoracic Society's recommendations [37,38]. An ethical framework of allocation of ICU resources using clinical judgement including a closed system that offers reciprocity, attention to general concerns of justice, respect for individual variations, explicitness, and a review of the decision making process should be advocated by the multidisciplinary group of physicians caring for these patients [39]. Consequently, decision support algorithms utilizing this ethical framework should be explored.

\section{CONCLUSION}

The PRFI and "expert opinion" are robust predictors of mortality and respiratory failure, respectively, in noncardiac surgical patients. Longer lengths of hospital stay and complication rates in patients of intermediate PRFI risk assigned to an ICU versus a high intensity unit or ward should prompt further scientific investigation in the form of clinical trials to aid in the decision making process of which patients to safely allocate to high intensity units versus the ICU postoperatively.

\section{COMPETING INTERESTS}

The authors declare that they have no competing interests in the conduct, analysis and interpretation of the study results.

\section{AUTHORS CONTRIBUTION}

DK contributed the conception and design of the study, the acquisition of the data, the data analysis and interpretation of the data, and in drafting and revising the manuscript. SN contributed to the interpretation of the data and in revising the manuscript for important intellectual content. BL contributed to the primary data analysis, the interpretation of the data analysis, and in revising the manuscript. All three authors have given final approval of the final version to be published.

\section{REFERENCES}

[1] Angus, D.C., Kelley, M.A., Schmitz, R.J., White, A., Popovich Jr., J., et al. (2000) Current and projected workforce requirements for care of the critically ill and patients with pulmonary disease: Can we meet the requirements of an aging population? The Journal of the American Medical Association, 284, 2762-2770. doi:10.1001/jama.284.21.2762

[2] Milbrandt, E.B., Kersten, A., Rahim, M.T., Dremsizov, T.T., Clermont, G., Cooper, L.M., et al. (2008) Growth of intensive care unit resource use and its estimated cost in Medicare. Critical Care Medicine, 36, 2504-2510. doi:10.1097/CCM.0b013e318183ef84

[3] Needham, D.M., Bronskill, S.E., Sibbald, W.J., Pronovost, P.J. and Laupacis, A. (2004) Mechanical ventilation in Ontario, 1992-2000: Incidence, survival, and hospital bed utilization of noncardiac surgery adult patients. Critical Care Medicine, 32, 1504-1509. doi:10.1097/01.CCM.0000129972.31533.37

[4] Goldman, L., Caldera, D.L., Nussbaum, S.R., Southwick, F.S., Krogstad, D., Murray, B., et al. (1977) Multifactorial index of cardiac risk in noncardiac surgical procedures. The New England Journal of Medicine, 297, 845850. doi:10.1056/NEJM197710202971601

[5] Arozullah, A.M., Khuri, S.F., Henderson, W.G. and Daley, J. (2001) Development and validation of a multifactorial risk index for predicting postoperative pneumonia after major noncardiac surgery. Annals of Internal Medicine, 135, 847-857.

[6] Arozullah, A.M., Daley, J., Henderson, W.G. and Khuri, S.F. (2000) Multifactorial risk index for predicting postoperative respiratory failure in men after major noncardiac surgery. Annals of Surgery, 232, 242-253. doi:10.1097/00000658-200008000-00015

[7] Lee, T.H., Marcantonio, E.R., Mangione, C.M., Thomas, E.J., Polanczyk, C.A., Cook, E.F., et al. (1999) Derivation and prospective validation of a simple index for prediction of cardiac risk of major noncardiac surgery. Circulation, 100, 1043-1049.

doi:10.1161/01.CIR.100.10.1043

[8] Khuri, S.F., Henderson, W.G., Daley, J., Jonasson, O., Jones, R.S., Campbell Jr., D.A., et al. (2007) The patient safety in surgery study: Background, study design, and patient populations. Journal of the American College of Surgeons, 204, 1089-1102. doi:10.1016/j.jamcollsurg.2007.03.028

[9] Agency for Healthcare Research and Quality (2007) National healthcare quality report. Institute US Department 
of Health and Human Services, Agency for Healthcare Research and Quality, Rockville. AHRQ Pub. No. 080040

[10] Dhond, G., Ridley, S. and Palmer, M. (1998) The impact of a high-dependency unit on the workload of an intensive care unit. Anaesthesia, 53, 841-847. doi:10.1046/j.1365-2044.1998.00522.x

[11] Campeau, L. (1976) Letter: Grading of angina pectoris. Circulation, 54, 522-523.

[12] Hurst, J.W., Morris, D.C. and Alexander, R.W. (1999) The use of the New York Heart Association's classification of cardiovascular disease as part of the patient's complete Problem List. Clinical Cardiology, 22, 385-390. doi:10.1002/clc.4960220604

[13] Adams, R.D. and Victor, M. (1989) Principles of neurology. 4th Edition, McGraw-Hill Inc., New York, 1989.

[14] Le Gall, J.R., Klar, J., Lemeshow, S., Saulnier, F., Alberti, C., Artigas, A., et al. (1996) The logistic organ dysfunction system. A new way to assess organ dysfunction in the intensive care unit. The Journal of the American Medical Association, 276, 802-810. doi:10.1001/jama.276.10.802

[15] McNicol, L., Story, D.A., Leslie, K., Myles, P.S., Fink, M., Shelton, A.C., et al. (2007) Postoperative complications and mortality in older patients having non-cardiac surgery at three Melbourne teaching hospitals. Medical Journal of Australia, 186, 447-452.

[16] Manku, K., Bacchetti, P. and Leung, J.M. (2003) Prognostic significance of postoperative in-hospital complications in elderly patients. I. Long-term survival. Anesthesia \& Analgesia, 96, 583-589.

[17] Cendan, J.C., Abu-aouf, D., Gabrielli, A., Caruso, L.J., Rout, W.R., Hocking, M.P., et al. (2005) Utilization of intensive care resources in bariatric surgery. Obesity Surgery, 15, 1247-1251. doi:10.1381/096089205774512681

[18] Helling, T.S., Willoughby, T.L., Maxfield, D.M. and Ryan, P. (2004) Determinants of the need for intensive care and prolonged mechanical ventilation in patients undergoing bariatric surgery. Obesity Surgery, 14, 1036-1041. doi:10.1381/0960892041975488

[19] Bertges, D.J., Goodney, P.P., Zhao, Y., Schanzer, A., Nolan, B.W., Likosky, D.S., et al. (2000) The Vascular Study Group of New England Cardiac Risk Index (VSG-CRI) predicts cardiac complications more accurately than the Revised Cardiac Risk Index in vascular surgery patients. Journal of Vascular Surgery, 52, 674-683.

[20] Ford, M.K., Beattie, W.S. and Wijeysundera, D.N. (2012) Systematic review: Prediction of perioperative cardiac complications and mortality by the revised cardiac risk index. Annals of Internal Medicine, 152, 26-35.

[21] Callaghan, C.J., Lynch, A.G., Amin, I., Fazel, M., Lindop, M.J., Gaunt, M.E., et al. (2005) Overnight intensive recovery: Elective open aortic surgery without a routine ICU bed. European Journal of Vascular and Endovascular Surgery, 30, 252-258. doi:10.1016/i.ejvs.2005.03.004

[22] Ryan, D. and McGreal, G. (2010) Why routine intensive care unit admission after elective open infrarenal Abdominal Aortic Aneurysm repair is no longer an evidence based practice. Surgeon, 8, 297-302.

\section{doi:10.1016/i.surge. 2010.05 .003}

[23] Podore, P.C. and Throop, E.B. (1999) Infrarenal aortic surgery with a 3-day hospital stay: A report on success with a clinical pathway. Journal of Vascular Surgery, 29, 787-792. doi:10.1016/S0741-5214(99)70204-1

[24] Terada, Y., Inoue, S., Tanaka, Y., Kawaguchi, M., Hirai, K. and Furuya, H. (2010) The impact of postoperative intensive care on outcomes in elective neurosurgical patients in good physical condition: A single centre propensity case-matched study. Canadian Journal of Anesthesia, 57, 1089-1094. doi:10.1007/s12630-010-9393-2

[25] Squadrone, V., Coha, M., Cerutti, E., Schellino, M.M., Biolino, P., Occella, P., et al. (2005) Continuous positive airway pressure for treatment of postoperative hypoxemia: A randomized controlled trial. The Journal of the American Medical Association, 293, 589-595. doi:10.1001/jama.293.5.589

[26] Devereaux, P.J., Yang, H., Yusuf, S., Guyatt, G., Leslie, K., Villar, J.C., et al. (2008) Effects of extended-release metoprolol succinate in patients undergoing non-cardiac surgery (POISE trial): A randomised controlled trial. Lancet, 371, 1839-1847. doi:10.1016/S0140-6736(08)60601-7

[27] Lees, N., Hamilton, M. and Rhodes, A. (2009) Clinical review: Goal-directed therapy in high risk surgical patients. Critical Care, 13, 231. doi:10.1186/cc8039

[28] Sandham, J.D., Hull, R.D., Brant, R.F., Knox, L., Pineo, G.F., Doig, C.J., et al. (2003) A randomized, controlled trial of the use of pulmonary-artery catheters in high-risk surgical patients. The New England Journal of Medicine, 348, 5-14. doi:10.1056/NEJMoa021108

[29] Chopra, V. and Eagle, K.A. (2010) Perioperative beta-blockers for cardiac risk reduction: Time for clarity. JAMA, 303, 551-552. doi:10.1001/jama.2010.68

[30] Cavaliere, F., Conti, G., Costa, R., Masieri, S., Antonelli, M. and Proietti, R. (2008) Intensive care after elective surgery: A survey on 30-day postoperative mortality and morbidity. Minerva Anestesiologica, 74, 459-468.

[31] Rose, D.K., Cohen, M.M. and DeBoer, D.P. (1996) Cardiovascular events in the postanesthesia care unit: Contribution of risk factors. Anesthesiology, 84, 772-781. doi:10.1097/00000542-199604000-00003

[32] Lee, A., Lum, M.E., O’Regan, W.J. and Hillman, K.M. (1998) Early postoperative emergencies requiring an intensive care team intervention. The role of ASA physical status and after-hours surgery. Anaesthesia, 53, 529-535. doi:10.1046/j.1365-2044.1998.00395.x

[33] Rosenberg, A.L. and Watts, C. (2000) Patients readmitted to ICUs ${ }^{*}$ : A systematic review of risk factors and outcomes. Chest, 118, 492-502. doi:10.1378/chest.118.2.492

[34] Ware, J.H. (2006) The limitations of risk factors as prognostic tools. The New England Journal of Medicine, 355, 2615-2617. doi:10.1056/NEJMp068249

[35] Ely, E.W., Inouye, S.K., Bernard, G.R., Gordon, S., Francis, J., May, L., et al. (2001) Delirium in mechanically ventilated patients. The Journal of the American Medical Association, 286, 2703-2710. doi:10.1001/jama.286.21.2703 
[36] Guenther, U., Popp, J., Koecher, L., Muders, T., Wrigge, H., Ely, E.W., et al. (2010) Validity and reliability of the CAM-ICU Flowsheet to diagnose delirium in surgical ICU patients. Journal of Critical Care, 25, 144-151. doi:10.1016/j.jcrc.2009.08.005

[37] American Thoracic Society (1997) Fair allocation of intensive care unit resources. American Journal of Respiratory and Critical Care Medicine, 156, 1282-1301.
[38] Kelley, M.A., Angus, D., Chalfin, D.B., Crandall, E.D., Ingbar, D., Johanson, W., et al. (2004) The critical care crisis in the United States: A report from the profession. Chest, 125, 1514-1517. doi:10.1378/chest.125.4.1514

[39] Hurst, S.A. and Danis, M. (2007) A framework for rationing by clinical judgment. Kennedy Institute of Ethics Journal, 17, 247-266. doi:10.1353/ken.2007.0021 


\section{APPENDIX 1. INCLUSION CRITERIA}

1) All patients going for vascular, thoracic, pancreatic, or esophagectomy surgery, who are being seen by $\geq 1$ Specialists (Bronchoscopy or carotid endarterectomies are excluded).

2) All patients going for orthopedic spinal or neurosurgery who are being seen by $\geq 1$ Specialists and have any one of the disease states listed below (Spinal includes discectomy, decompression, fusion, instrumentation).

3) All patients going for general surgery who are being seen by $\geq 1$ Specialists and have any one of the disease states listed, (two if hypertensive), or who are less than fully independent (see definitions below) (General surgery includes all mastectomies, abdominal/laproscopic surgery [including umbilical, epigastric and inguinal hernia]).

\begin{tabular}{|c|c|}
\hline & Disease States \\
\hline \multirow[t]{5}{*}{ Myocardial } & Angina (Canadian Cardiovascular Society Classification) \\
\hline & Arrhythmia \\
\hline & Valvular heart disease \\
\hline & Myocardial Infarction \\
\hline & Congestive Heart Failure (New York Heart Association Classification) \\
\hline \multirow[t]{3}{*}{ Vascular } & Hypertension (must have another if undergoing general surgery) \\
\hline & Peripheral vascular disease \\
\hline & Cerebrovascular disease \\
\hline \multirow[t]{3}{*}{ Pulmonary } & Chronic obstructive pulmonary disease \\
\hline & Asthma \\
\hline & Interstitial lung disease Obstructive sleep apnea (with or without treatment) \\
\hline \multirow[t]{6}{*}{ Neurologic } & Dementia \\
\hline & Hemiplegia or paraplegia \\
\hline & Seizure disorder \\
\hline & Neuropathy \\
\hline & Myopathy \\
\hline & Any significant spinal disease [at the discretion of investigator] \\
\hline RHEMATOLOGIC & $\begin{array}{c}\text { Any significant rhematlogic disease [at the discretion of investigator] —includes SLE, Rheumatoid } \\
\text { arthiritis but not Osteoarthritis }\end{array}$ \\
\hline \multirow[t]{5}{*}{ Gastrointestinal } & Peptic ulcer disease \\
\hline & Gastroesophageal reflux disease \\
\hline & Gastrointestinal bleeding \\
\hline & Inflammatory bowel disease \\
\hline & Mild, moderate or severe liver disease \\
\hline \multirow[t]{3}{*}{ Endocrine } & Diabetes, on insulin or oral hypoglycemics \\
\hline & Diabetes with complications High BMI $(\geq 30)$ \\
\hline & Other significant endocrine disorders [at the discretion of investigator] \\
\hline \multirow[t]{2}{*}{ Renal } & Acute renal failure \\
\hline & Chronic renal failure \\
\hline \multirow[t]{4}{*}{ Cancer/Immune } & Any malignancy, including lymphoma and leukemia - excluded if surgical resection $>5$ years \\
\hline & Metastatic solid tumor \\
\hline & HIV-AIDS \\
\hline & Bleeding disorders and coagulpopathy \\
\hline
\end{tabular}

Partially Dependent: Requires equipment/devices + assistance from another person for some ADL. i.e.) patients from a nursing home, on kidney dialysis or home ventilation support, yet maintains some independent function; Totally Dependent: Cannot perform any activities of daily living for him/her self; includes patients who are totally dependent on nursing care, such as a dependent nursing home patient. 


\section{APPENDIX 2. PATIENT PREOPERATIVE ALLOCATION BY "EXPERT OPINION" AND HIGHEST POSTOPERATIVE LEVEL OF CARE}

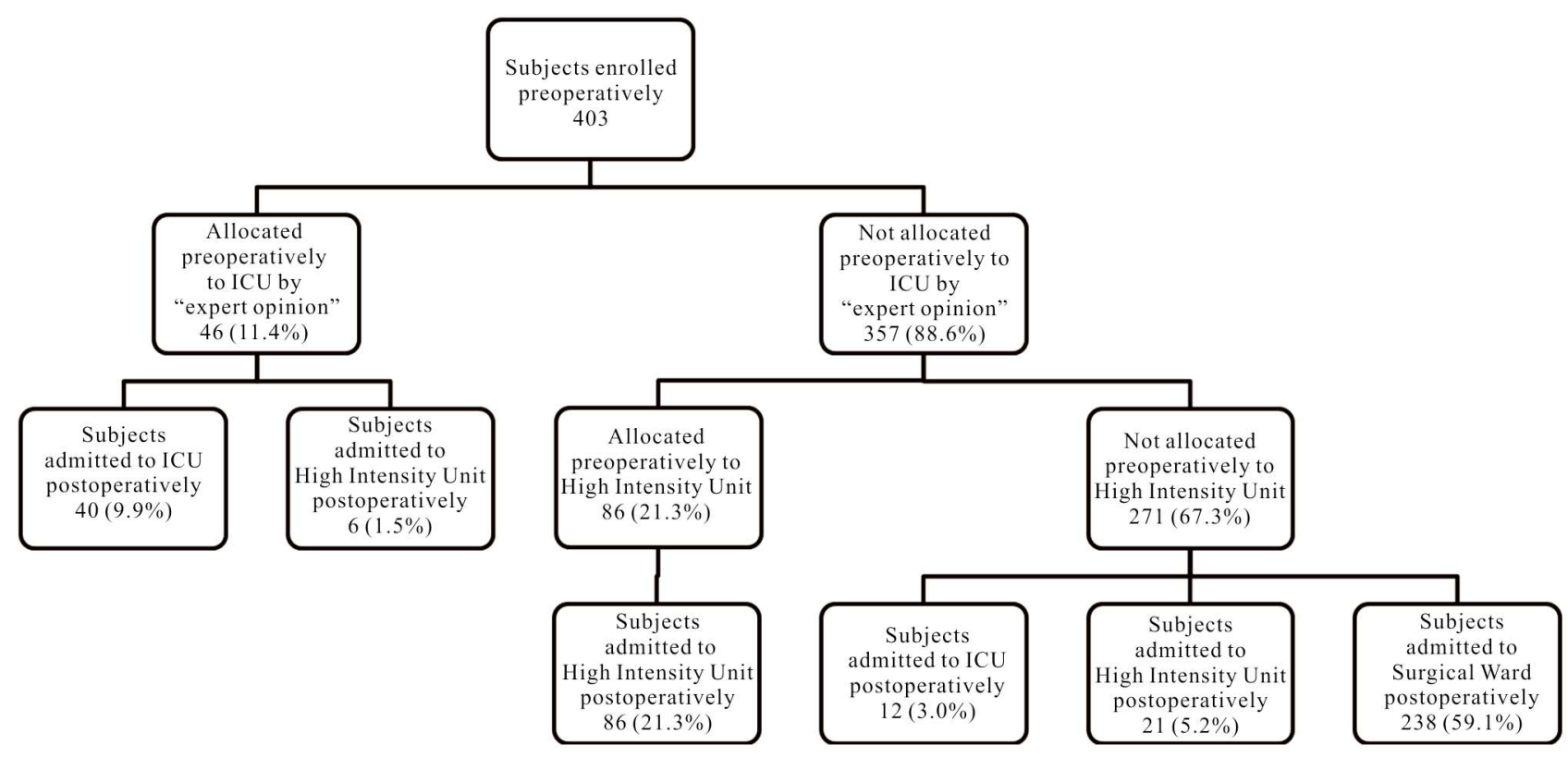

\section{ABBREVIATIONS}

BMI Body mass index;

FEV1 Forced expiratory volume in one second;

LOD Logistic organ dysfunction score

(Includes: Glasgow Coma Score, heart rate, systolic blood pressure, urea, creatinine, urine output, $\mathrm{PaO}_{2} / \mathrm{FIO}_{2}$, white blood cell count, platelet count, bilirubin, INR);

RCRI Revised cardiac risk index
(Includes: high-risk type of surgery, history of ischemic heart disease, congestive heart failure, cerebrovacular disease, preoperative treatment with insulin, preoperative serum creatinine $>2.0 \mathrm{mg} / \mathrm{dL}$ );

PRFI Preoperative respiratory failure index

(Includes: type of surgery, emergency surgery, albumin $<30 \mathrm{~g} / \mathrm{L}$, blood urea nitrogen $>30 \mathrm{mg} / \mathrm{dL}$, partially or fully dependent functional status, history of chronic obstructive pulmonary disease, age). 